Lenguas entre dos fuegos. Intérpretes en la Guerra Civil española (1936-1939)

Jesús BAIgORRI JALÓN

Granada, Comares, 2019, 216 págs.

Francisca García Luque

Lenguas entre dos fuegos Intérpretes en la Guerra Civil española (1936-1939)

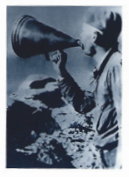

Insis Bamgerri jalón

EDITORIA COMARE
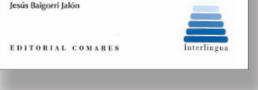

zadas como un arma más, que ayudó a poner en marcha la maquinaria bélica, a veces ofensiva y a veces defensiva. A la luz de la documentación hallada, ambos bandos fueron conscientes ya desde el inicio de la importancia que tendrían los intérpretes para la comunicación en un conflicto en el que intervendrían personas que hablaban muchas lenguas distintas. Si tenemos en cuenta que algunos historiadores consideran que la Guerra Civil española fue, entre otras muchas cosas, un banco de pruebas para lo que sucedería después en la Segunda Guerra Mundial, el funcionamiento de estas prácticas de interpretación en un contexto altamente internacional tiene un gran valor.

En un segundo momento, el estudio se detiene en el análisis de las lenguas como obstáculos y al mismo tiempo vehículos de la comunicación en el contexto bélico. En el bando sublevado, la procedencia de los soldados que lo integraban era múltiple: los provenientes del protectorado español de Marruecos, los alemanes, los italianos, pero también pequeños grupos de franceses, irlandeses y soldados de otros países. En el bando republicano había españoles, rusos y más de cincuenta nacionalidades diferentes integradas en las Brigadas Internacionales. Por lo tanto, ambos bandos tuvieron que incorporar a sus filas a personas que actuaran como intérpretes, que no siempre compartían un mismo perfil. Se trató de profesionales en unos casos (las intérpretes soviéticas en el bando republicano o los miembros de la Legión Cóndor en el bando sublevado), mientras que en otros tan solo eran hablantes o meros conocedores de varias lenguas que, en función de las circunstancias y las necesidades, fueron utilizados por los mandos para una comunicación a veces muy precaria, ayudada por gestos, por el contexto bélico, que empujaba a maximizar cualquier recurso, y por un sentimiento de pertenecer al mismo bando que urgía a entenderse de cualquier manera y conseguir el 
596

objetivo común: la derrota enemiga. Estos intérpretes ejercieron su labor en unas circunstancias muy complejas donde las barreras culturales, los acentos, la procedencia social e incluso ideológica de intérpretes y usuarios se hicieron visibles y donde todos tuvieron que adaptarse y aprender para lograr que la comunicación fluyese.

El tercer capítulo del estudio se centra en el papel del intérprete como agente de la comunicación en el contexto de la Guerra Civil. Lo primero que destaca el investigador es que, aunque durante la República había algunos organismos en los que existían servicios de interpretación donde se contaba con criterios para seleccionar al personal, la guerra hizo que los requisitos lingüísticos se relajaran por razones previsibles: un conflicto armado altera totalmente las prioridades y los procesos de selección, imponiendo una nueva lógica a la manera de funcionar donde lo que prima es que la comunicación funcione. El nexo de unión entre todas las personas que ejercieron en la práctica como intérpretes era la convicción de que, con sus conocimientos lingüísticos, podían ayudar a la causa y serle leales, aunque fuera una ocupación meramente transitoria. A continuación, Baigorri señala tres características comunes a todos los intérpretes. La primera es que su incorporación al servicio se producía en el caso de que sus superiores los considerasen aptos para las labores que tenían que desempeñar, con independencia de que sus conocimientos lingüísticos se pudieran equiparar con los de los intérpretes actuales o de que hubieran sido adquiridos en contextos familiares, educativos o sencillamente por los vaivenes de la azarosa vida de algunos de ellos. La segunda es que siempre eran intérpretes «de parte», en el sentido de que estaban adscritos a una unidad o servicio y eran, salvo excepciones muy puntuales, personas absolutamente afines a la ideología del bando en cuestión. La tercera es que todos fueron aprendiendo de la práctica, detectando problemas y carencias y poniendo en marcha soluciones ad hoc a medida que avanzaba el conflicto; y esto, a pesar de que la intervención de todos ellos no se extendió durante toda la guerra, sino que se limitó a unos meses o en algunos casos un poco más allá.

Por lo que respecta al desempeño de la interpretación y las condiciones de trabajo, el estudio indica que en la mayoría de los casos la interpretación se realizaba directamente entre la LO y la LM, aunque a veces fue necesario recurrir al relé. No se utilizó nunca la interpretación simultánea ni tampoco existen testimonios escritos sobre el uso del susurro, sino que mayoritariamente se recurrió a la consecutiva corta. Se incide además en factores que hoy en día conocemos bien, pero que en aquel momento surgieron como obstáculos que hubo que solventar sobre la marcha: la presencia de terminología en un contexto bélico, los acentos o la diversidad de registros que un mismo intérprete debía manejar. Este capítulo incluye múltiples ejemplos de situaciones variadas en las que el intérprete no se limitaba a trasladar un contenido, sino que a veces acortaba determinadas partes, otras veces omitía deliberadamente algo; en resumen, asumía un papel de mediador en el que no se limitaba a trasmitir una información, sino que valoraba qué era necesario y qué no. Por lo que respecta a las condiciones de trabajo, el autor señala que a menudo estas no diferían mucho de las del resto de los soldados, de modo que también los intérpretes caían heridos y morían en combate, aunque parece ser que en un número menor a otras categorías. Pocas veces llevaban distintivo en su uniforme y a veces ni siquiera portaban ropas militares sino civiles. Las recompensas a su labor vinieron muchas veces en forma de condecoraciones al finalizar el conflicto. Unas recompensas que reconocían el esfuerzo de haber servido fielmente a su propósito, con las limitaciones humanas comprensibles en un contexto muy frágil y cambiante donde las exigencias de comunicación eran muchas y variadas, surgían 
constantemente consideraciones éticas a las que tenían que hacer frente y donde todos, intérpretes y usuarios, tuvieron que adaptarse.

El capítulo cuarto del estudio se adentra en los diferentes entornos en los que se utilizó la interpretación para describir esa Babel en la que se convirtió España, especialmente los primeros dos años del conflicto, cuando a los conocimientos lingüísticos de quienes actuaban como intérpretes se unían el deseo y la necesidad imperiosa de entenderse. El repaso se detiene muy brevemente en los contextos de interpretación más habituales, empezando por los interrogatorios de prisioneros y los campos de concentración, donde se prestaba especial atención a las necesidades de comunicación de los soldados extranjeros debido a la repercusión internacional que su trato podía tener de cara a la guerra propagandística. La interpretación y la traducción también fueron prácticas habituales dentro de las estrategias de propaganda y la censura en ambos bandos, en los que a los intérpretes les tocaba, por ejemplo, acompañar a mandatarios o personalidades extranjeras que visitaban el país. El libro recoge y analiza diversos testimonios de intérpretes que relataban dificultades y sentimientos de distinta naturaleza. La dureza de interpretar a la población civil víctima de los bombardeos, como el de la carretera de Almería, cuando contaban su experiencia a quienes venían a España; la emoción y la solemnidad de interpretar en un entierro; la responsabilidad y la precisión de la interpretación en los hospitales y los entornos sanitarios, donde una comunicación correcta y concisa podía ser vital para salvar una vida; y la tristeza de ver cómo un soldado moría sin tener a alguien que pudiera recoger sus últimas palabras porque nadie hablaba ese idioma en particular. Este breve repaso acaba con la desmovilización, cuando los soldados extranjeros se retiraron del conflicto y también fue necesaria la intervención de intérpretes.
El quinto y último capítulo se detiene muy brevemente en la intrahistoria de algunos de los intérpretes con nombre y apellidos de los que el autor tuvo constancia en el transcurso de la investigación. Los datos incluidos, que no son exhaustivos sino ilustrativos, dejan ver algunas pinceladas de quiénes fueron aquellas personas, mayoritariamente hombres jóvenes, de orígenes muy diversos, que asumieron la difícil labor de interpretar en un contexto bélico. El primer grupo al que se refiere es el de los intérpretes de la Legión Cóndor, unos 650, bien pagados y con formación previa. Seguidamente pasa a hablar de los intérpretes de las brigadas internacionales, que empezaron su labor en Albacete, ciudad elegida como cuartel general. Entre ellos está un miembro del partido comunista francés, yugoslavo de origen y deseoso de combatir el fascismo; un croata que en su periplo de vuelta a su país decidió tomar parte en la guerra; los hijos de los mineros españoles que habían sido enviados a Gales años atrás, impregnados en la lucha de clases desde la generación anterior, que decidieron unirse a las brigadas internacionales; una mujer francesa que llegó a ocupar un cargo de oficial intérprete, o un joven que por padecer una enfermedad pulmonar no pudo ir al frente pero decidió poner sus conocimientos lingüísticos al servicio de la causa republicana. Capítulo aparte merecen los intérpretes de los asesores soviéticos, la mitad de ellos mujeres, con formación previa antes de llegar a España, que ejercieron labores de interpretación al tiempo que de propaganda al servicio del régimen de Stalin. El capítulo se cierra con dos personajes calificables como anecdóticos: un contrabandista indio y quien se convertiría décadas después en alcalde de Cáceres.

El epílogo del libro alude a las necesidades de interpretación que siguieron existiendo una vez acabada la guerra en otros contextos, como los campos de refugiados en Francia tras la victoria franquista o durante el siguiente gran conflicto 
598 bélico, la Segunda Guerra Mundial. Al igual que había sucedido durante la guerra en España, en determinados contextos militares la interpretación estuvo más integrada operativamente, mientras que en otros la solución fue de nuevo la improvisación y la buena voluntad.

A luz del contenido aquí resumido, podemos concluir que se trata de un estudio minucioso, de largo recorrido, con una labor archivística muy extensa e impregnado de cierto valor reivindicativo, para dar a conocer una actividad poco visible pero necesaria que desempeñaron hombres y mujeres en un contexto muy difícil, el de una guerra. Como desgraciadamente los conflictos bélicos siguen formando parte de nuestras vidas y en ellos siguen interviniendo los intérpretes, este trabajo es sin duda una obra de referencia muy necesaria para entender mejor las condiciones que ese contexto impone al ejercicio de la interpretación. Este trabajo contribuye, además, a conocer más a fondo la historia de esta profesión tan exigente, apasionante y a veces tan dura a partes iguales.

\section{Subtitling: Concepts and Practices}

\section{Jorge Díaz Cintas y Aline Remael}

Londres y Nueva York, Routledge, 2021, 273 págs.

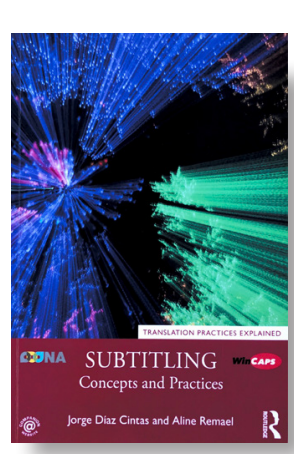

Nieves Jiménez Carra Uno de los libros referentes en la investigación en traducción audiovisual (TAV) y, en concreto, en la modalidad de subtitulado es, sin duda, Audiovisual Translation: Subtitling, escrito por Jorge Díaz Cintas y Aline Remael (publicado por St. Jerome en 2007 y posteriormente por Routledge en 2014). Debido a la continua expansión de las distintas modalidades de TAV, motivada muy especialmente por la irrupción de las plataformas de visionado en línea y, como consecuencia, por una mayor globalización del mercado audiovisual, es necesario actualizar los conceptos y las prácticas que rigen la traducción en este ámbito.

Precisamente por ello, e inspirados por su anterior publicación, Jorge Díaz Cintas y Aline Remael, investigadores de TAV reconocidos a nivel mundial, firman este nuevo volumen destinado a docentes, estudiantes, investigadores y profesionales y centrado en la teoría y la práctica del subtitulado.

Subtitling: Concepts and Practices se presenta como un compendio de información teórica, ejercicios prácticos, técnicas y estrategias de traducción y, como se indica en la introducción, como «a truly multimedia package». De hecho, cuenta con un sitio web con recursos adicionales y también se proporciona acceso durante un periodo de tiempo al software de subtitulado Wincaps Q4 y a un periodo de prueba en la plataforma de subtitulado en la nube OONA.

El libro cuenta con nueve capítulos, sin contar el de referencias bibliográficas, que van desde la información general a la específica. En cada capítulo se comienza sugiriendo una lista de preguntas o propuestas preliminares y se finaliza con ejercicios divididos por niveles, de los cuales la mayoría se encuentran disponibles en la web que acompaña al libro. Estos ejercicios, dependiendo del capítulo, están centrados en la reflexión sobre aspectos teóricos o en prácticas de subtitulado.

El capítulo 1, denominado Reconceptualizing subtitling, constituye una visión actualizada del subtitulado. Se exponen los cambios que ha experimentado la TAV a lo largo de las últimas décadas, pasando por las modalidades que se incluyen bajo el paraguas de esta denomina- 